\title{
Relationship of thyroid function with intracranial arterial stenosis and carotid atheromatous plaques in ischemic stroke patients with euthyroidism
}

\author{
Junfeng Liu ${ }^{1, *}$, Xiaoyang Cui ${ }^{2, *}$, Deren Wang ${ }^{1}$, Simiao Wu ${ }^{1}$, Yao Xiong ${ }^{1}$, Shihong \\ Zhang ${ }^{1}$, Bo Wu ${ }^{1}$ and Ming Liu ${ }^{1}$ \\ ${ }^{1}$ Department of Neurology, Stroke Clinical Research Unit, West China Hospital, Sichuan University, Chengdu, P.R. China \\ 2 Department of Respiratory and Critical Care Medicine, China-Japan Friendship Hospital, Beijing, P.R. China \\ * The first two authors contributed equally to this work \\ Correspondence to: Ming Liu, email: wyplmh@hotmail.com \\ Keywords: free triiodothyronine, free thyroxine, thyroid-stimulating hormone, intracranial artery stenosis, carotid atheromatous \\ plaques \\ Received: October 02, $2016 \quad$ Accepted: January 16, $2017 \quad$ Published: January 28, 2017 \\ Copyright: Liu et al. This is an open-access article distributed under the terms of the Creative Commons Attribution License 3.0 (CC BY 3.0), \\ which permits unrestricted use, distribution, and reproduction in any medium, provided the original author and source are credited.
}

\section{ABSTRACT}

This study aimed to help clarify the possible relationships of thyroid function with intracranial arterial stenosis or carotid atheromatous plaques in ischemic stroke patients with euthyroidism. We retrospectively reviewed the medical records of a consecutive series of ischemic stroke patients prospectively entered into the Chengdu Stroke Registry between February 2010 and March2012. We performed univariate and multivariate analysis to assess possible relationships of thyroid function with intracranial artery stenosis or carotid atheromatous plaques. Of the 172 patients analyzed (42 women; $61.7 \pm 14.0$ years old), $62(32.0 \%)$ had carotid atheromatous plaques, and $81(47.1 \%)$ had intracranial artery stenosis. Free thyroxine levels were lower in patients with carotid atheromatous plaques than in patients without plaques (15.80 \pm 2.09 vs. $16.92 \pm 2.69, P=0.005)$.After adjusting for age, gender, hyperlipidemia, and previous smoking, free thyroxine levels were independently associated with carotid atheromatous plaques (OR $0.73,95 \% \mathrm{CI} 0.54-0.99, P=0.04$ ). In contrast, thyroid function indicators showed no associations with intracranial arterial stenosis. In conclusion, low free thyroxine levels were independently associated with carotid atheromatous plaques in ischemic stroke patients with euthyroidism, but thyroid function indicators were not associated with intracranial artery stenosis.

\section{INTRODUCTION}

Stroke is the second most common cause of death after cancer and a leading cause of adult disability worldwide [1]. Approximately $85 \%$ of strokes are ischemic strokes [2]. Stroke incidence appears to be increasing, and the associated economic costs are staggering [3].Population-or hospital-based prospective studies and large randomized trials have identified carotid plaques [4-6] and major intracranial arterial stenosis [7-9 ]as major causes of stroke, especially in Asians, Blacks, and Hispanics. Thus, identifying easily screenable factors that may correlate with the presence or severity of carotid plaques or major intracranial arterial stenosis may help identify individuals at risk of stroke.

Thyroid dysfunction, including overt hyper-or hypothyroidism as well as subclinical thyroid disease, has been associated with cardiovascular disease [10], cerebrovascular risk $[11,12]$, atherosclerosis $[13,14]$ and thickening of the carotid artery intima media $[15,16]$. In addition, thyroid function at the low end of the normal range (still within euthyroid limits) has been associated with increased levels of inflammatory markers [17], thickening of the carotid intima media [18-21], stenosis of the internal carotid artery [22], and ulceration of carotid artery plaques [23].These associations suggest that thyroid 
Table 1: Baseline characteristics of ischemic stroke patients stratified by carotid atheromatous plaques or intracranial artery stenosis

\begin{tabular}{|l|c|c|c|c|c|c|}
\hline & $\begin{array}{c}\text { Plaques } \\
(\boldsymbol{n}=\mathbf{6 2})\end{array}$ & $\begin{array}{c}\text { No plaques } \\
(\boldsymbol{n}=\mathbf{1 1 0})\end{array}$ & $\boldsymbol{P}$ & $\begin{array}{c}\text { Stenosis } \\
(\boldsymbol{n}=\mathbf{8 1})\end{array}$ & $\begin{array}{c}\text { No stenosis } \\
(\boldsymbol{n}=\mathbf{9 1})\end{array}$ & $\boldsymbol{P}$ \\
\hline Age, yr & $64.82 \pm 13.48$ & $59.91 \pm 14.04$ & $\mathbf{0 . 0 3}$ & $61.16 \pm 14.56$ & $62.14 \pm 13.56$ & 0.65 \\
\hline Male & $54(87.1 \%)$ & $76(69.1 \%)$ & $\mathbf{0 . 0 0 8}$ & $61(75.3 \%)$ & $69(75.8 \%)$ & 0.94 \\
\hline Hypertension & $32(51.6 \%)$ & $63(57.3 \%)$ & 0.47 & $46(56.8 \%)$ & $49(53.8 \%)$ & 0.70 \\
\hline Diabetes mellitus & $14(22.6 \%)$ & $16(14.5 \%)$ & 0.18 & $18(22.2 \%)$ & $12(13.2 \%)$ & 0.12 \\
\hline Hyperlipidemia & $10(16.1 \%)$ & $6(5.5 \%)$ & $\mathbf{0 . 0 2}$ & $9(11.1 \%)$ & $7(7.7 \%)$ & 0.44 \\
\hline Atrial fibrillation & $3(4.8 \%)$ & $9(8.2 \%)$ & 0.41 & $9(11.1 \%)$ & $3(3.3 \%)$ & 0.05 \\
\hline Coronary heart disease & $7(11.3 \%)$ & $8(7.3 \%)$ & 0.37 & $5(6.2 \%)$ & $10(11.0 \%)$ & 0.26 \\
\hline Previous stroke & $8(12.9 \%)$ & $15(13.6 \%)$ & 0.89 & $14(17.3 \%)$ & $9(9.9 \%)$ & 0.16 \\
\hline Smoking consumption & $32(51.6 \%)$ & $37(33.6 \%)$ & $\mathbf{0 . 0 2}$ & $32(39.5 \%)$ & $37(40.7 \%)$ & 0.88 \\
\hline Alcohol consumption & $17(27.4 \%)$ & $26(23.6 \%)$ & 0.58 & $21(25.9 \%)$ & $22(24.2 \%)$ & 0.79 \\
\hline TSH, mU/L & $1.79 \pm 0.88$ & $1.91 \pm 1.01$ & 0.43 & $1.77 \pm 0.99$ & $1.96 \pm 0.93$ & 0.20 \\
\hline FT4, pmol/L & $15.80 \pm 2.09$ & $16.92 \pm 2.69$ & $\mathbf{0 . 0 0 5}$ & $16.70 \pm 2.71$ & $16.35 \pm 2.38$ & 0.37 \\
\hline FT3, pmol/L & $4.09 \pm 0.77$ & $3.99 \pm 0.85$ & 0.48 & $3.99 \pm 0.80$ & $4.06 \pm 0.85$ & 0.58 \\
\hline
\end{tabular}

Table 2: Multivariate analysis to identify association of thyroid function (treated in continuous parameters) with carotid atheromatous plaques

\begin{tabular}{|l|c|c|c|}
\hline \multicolumn{1}{|c|}{} & OR & $\mathbf{9 5 \% C I}$ & $\boldsymbol{P}$ \\
\hline Age, yr & 1.03 & $1.01-1.06$ & 0.02 \\
\hline Male & 2.02 & $0.76-5.35$ & 0.16 \\
\hline Smoking consumption & 1.58 & $0.74-3.37$ & 0.23 \\
\hline Hyperlipidemia & 2.56 & $0.82-7.99$ & 0.11 \\
\hline TSH, mU/L & 0.90 & $0.62-1.32$ & 0.80 \\
\hline FT4, pmol/L & $\mathbf{0 . 8 2}$ & $\mathbf{0 . 7 0 - 0 . 9 6}$ & $\mathbf{0 . 0 1}$ \\
\hline FT3, pmol/L & 1.38 & $0.89-2.15$ & 0.16 \\
\hline
\end{tabular}

function may be associated with intracranial arterial stenosis and/or carotid atheromatous plaques in ischemic stroke patients, even in patients with euthyroidism. However, we are unaware of published work on this question.

Therefore the present study investigated the impact of thyroid function on intracranial arterial stenosis and carotid atheromatous plaques in ischemic stroke patients with euthyroidism.

\section{RESULTS}

During the study period, 308 patients suffering first-ever or recurrent ischemic stroke were enrolled in the Chengdu Stroke Registry. After excluding patients who met the exclusion criteria, 212 were analyzed closely for euthyroidism (Figure 1). Patients were excluded from this group because their fT3 and fT4 levels were in the normal range and TSH levels $>4.2 \mathrm{mU} / \mathrm{L}$, corresponding to subclinical hypothyroidism $(n=37)$; because their fT3 and fT4 levels were in the normal range and TSH levels $<0.27 \mathrm{mU} / \mathrm{L}$, corresponding to subclinical hyperthyroidism $(n=2)$; or because their fT3 and fT4 levels were elevated and TSH levels $<0.27 \mathrm{mU} / \mathrm{L}$, corresponding to overt hyperthyroidism $(\mathrm{n}=1)$. The remaining 172 patients with euthyroidism were included in the final analysis.

Age did not differ significantly between patients in the final analysis and those who were excluded (61.7 \pm 14.0 vs $63.2 \pm 14.3 \mathrm{yr}, P=0.339$ ). The proportion of women was significantly higher among excluded patients than included patients (43.4 vs 24.4\%, $P<0.001)$.

Among the 172 patients with euthyroidism, 81 (47.1\%) had intracranial artery stenosis, and 62(32.0\%) had atheromatous plaques in carotid arteries. Baseline characteristics of patients stratified according to the presence or absence of carotid atheromatous plaques or intracranial artery stenosis are presented in Table 1. Patients with carotid atheromatous plaques were older than those without plaques and more likely to be male, to have a smoking history, and to have hyperlipidemia. In contrast, patients with or without intracranial artery stenosis were similar in terms of age, gender, risk factors of stroke, as well as smoking and drinking status.

Levels of fT4 were significantly lower in patients with carotid atheromatous plaques than in patients without plaques, while these levels were similar between patients with or without intracranial artery stenosis (Table1). In the multivariate model (Table 2), fT4 levels were still independently associated with carotid atheromatous 
Table 3: Univariate analysis to identify association of thyroid function (treated categorically in quartiles) with carotid atheromatous plaques or intracranial artery stenosis

\begin{tabular}{|l|c|c|c|c|}
\hline & Quartile 1 & Quartile 2 & Quartile 3 & Quartile 4 \\
\hline TSH, mU/L & & & & \\
\hline Median (range) & $0.72(0.29-1.07)$ & $1.38(1.13-1.75)$ & $2.20(1.80-2.38)$ & $3.07(2.40-4.20)$ \\
\hline Patients with plaques, n/N (\%) & $18 / 43(41.9)$ & $15 / 43(34.9)$ & $16 / 43(37.2)$ & $13 / 43(30.2)$ \\
\hline OR (95\% CI) & $1.66(0.68-4.04)$ & $1.24(0.50-3.05)$ & $1.37(0.56-3.36)$ & Ref \\
\hline Patients with stenosis, n/N (\%) & $25 / 43(58.1)$ & $20 / 43(46.5)$ & $14 / 43(32.6)$ & $22 / 43(51.2)$ \\
\hline OR (95\% CI) & $1.33(0.57-3.11)$ & $0.83(0.36-1.94)$ & $0.46(0.19-1.11)$ & Ref \\
\hline FT4, pmol /L & & & & \\
\hline Median (range) & $14.00(11.24-14.92)$ & $15.43(14.94-16.06)$ & $17.00(16.09-17.99)$ & $19.32(18.02-26.92)$ \\
\hline Patients with plaques, n/N (\%) & $21 / 43(48.8)$ & $18 / 43(41.9)$ & $12 / 43(27.9)$ & $11 / 43(25.6)$ \\
\hline OR (95\% CI) & $\mathbf{2 . 7 8 ( 1 . 1 2 - 6 . 8 9 )}$ & $2.10(0.84-5.23)$ & $1.13(0.43-2.93)$ & Ref \\
\hline Patients with stenosis, n/N (\%) & $19 / 43(44.2)$ & $18 / 43(41.9)$ & $21 / 43(48.8)$ & $23 / 43(53.5)$ \\
\hline OR (95\% CI) & $0.69(0.29-1.61)$ & $0.63(0.27-1.47)$ & $0.83(0.36-1.94)$ & Ref \\
\hline FT3, pmol/L & & & & \\
\hline Median (range) & $3.14(1.67-3.46)$ & $3.90(3.48-4.08)$ & $4.27(4.09-4.57)$ & $5.00(4.58-6.52)$ \\
\hline Patients with plaques, n/N (\%) & $17 / 44(38.6)$ & $13 / 44(29.5)$ & $17 / 42(40.5)$ & $15 / 42(35.7)$ \\
\hline OR (95\% CI) & $1.13(0.47-2.72)$ & $0.76(0.31-1.87)$ & $1.22(0.51-2.96)$ & Ref \\
\hline Patients with stenosis, n/N (\%) & $21 / 44(47.7)$ & $19 / 44(43.2)$ & $21 / 42(50.0)$ & $20 / 42(47.6)$ \\
\hline OR (95\% CI) & $1.00(0.43-2.34)$ & $0.84(0.36-1.96)$ & $1.10(0.47-2.59)$ & Ref \\
\hline
\end{tabular}

Ref, reference; CI, confidence interval

Table 4: Logistic regression to identify association of thyroid function with carotid atheromatous plaques

\begin{tabular}{|c|c|c|c|}
\hline Indicator (in quartiles) & OR & $\mathbf{9 5 \%}$ CI & $\boldsymbol{P}$ \\
\hline TSH & 0.91 & $0.68-1.23$ & 0.55 \\
\hline FT4 & $\mathbf{0 . 7 3}$ & $\mathbf{0 . 5 4 - 0 . 9 9}$ & $\mathbf{0 . 0 4}$ \\
\hline FT3 & 1.00 & $0.74-1.35$ & 0.99 \\
\hline
\end{tabular}

Data were adjusted for age, gender, hyperlipidemia, and smoking consumption.

plaques. Levels of TSH and fT3 were similar between patients with or without carotid atheromatous plaques, and between patients with or without intracranial artery stenosis.

The raw (continuous) levels of TSH, fT4 and fT3 were then converted into quartiles (Table 3) in order to perform logistic regression to identify possible associations of thyroid function with carotid atheromatous plaques or intracranial artery stenosis. Only one significant association was found: patients in lower fT4 quartiles were at significantly higher risk of carotid atheromatous plaques than patients in the highest quartile. This relationship persisted even after adjusting for age, gender, hyperlipidemia, and smoking consumption (OR 0.73, 95\% CI 0.54-0.99, $P=0.04$, Table 4).

\section{DISCUSSION}

The present study suggests that low fT4 levels are independently associated with the presence of carotid atheromatous plaques in ischemic stroke patients with euthyroidism. Given that carotid plaques are associated with subsequent ischemic stroke [4-6], our data support the possibility that low-normal thyroid function can increase cerebrovascular risk, suggesting the need to improve thyroid screening and to redefine optimal ranges of thyroid hormone serum concentrations.

Our results are consistent with previous studies showing associations between low fT4 levels and elevated levels of inflammatory markers [17], mitral annular calcification [24], and thickening of the carotid intima media [18-21] in stroke patients with euthyroidism. Since our findings were obtained with a relatively large and inclusive sample of ischemic stroke patients, we strengthen the case for targeted screening of ischemic stroke patients with low-normal thyroid function for carotid atheromatous plaques.

The observed association between low fT4 levels and prevalence of carotid atheromatous plaques can be explained by several possible mechanisms. Low fT4 levels may promote atherosclerosis indirectly by increasing lipid levels, insulin resistance, and hypertension, as well as by impairing endothelial function [25-28]. In addition, thyroid hormones have a direct vasodilatory effect, acting mainly on vascular smooth muscle cells [29].Therefore low fT4 levels may facilitate the formation and/or growth of carotid atheromatous plaques. 
Possible factors may help explain why fT3 was not associated with plaques in our patients. These factors include the short half-life of fT3, the possibility that serum concentrations of fT3 do not accurately reflect concentrations in tissues, and the greater sensitivity of fT3 than fT4 to hyperthyroidism, which may not be associated with carotid artery plaques. Further work should verify and extend our findings about fT3 in ischemic stroke patients.

We observed no significant association between any of the three thyroid hormones and intracranial artery stenosis in our patients. These results are consistent with studies on young Chinese stroke patients with euthyroidism [30] and Chinese stroke patients with hyperthyroidism [31]. Those studies also found no association of TSH, fT4, or fT3 levels with intracranial artery stenosis. They did, however, find such stenosis to be associated with elevated thyroid autoantibodies. This association should be confirmed and extended in future work. The different association of thyroid indicators with carotid atheromatous plaques or intracranial artery stenosis may reflect that intra- and extracranial vessels differ in anatomic location as well as in atherosclerotic pathophysiology [32].

Indeed, intracranial arterial stenosis differs from carotid atheromatous plaques in epidemiology and risk factors. Stenosis occurred in $47.1 \%$ of our patients, while carotid plaques occurred in $32.0 \%$, similar to previous studies in Chinese [33] and other Asians [32, 34-37], suggesting that intracranial arterial stenosis is more prevalent among Asians. Moreover, we found carotid atheromatous plaques to correlate positively with age, gender, hypercholesterolemia and previous smoking, consistent with previous work[38]; such correlations were not observed for stenosis.

This study has some limitations. First, it was a retrospective, cross-sectional, hospital-based study, which means that cause-and-effect relationships between

308 potentially eligible patients with ischemic stroke

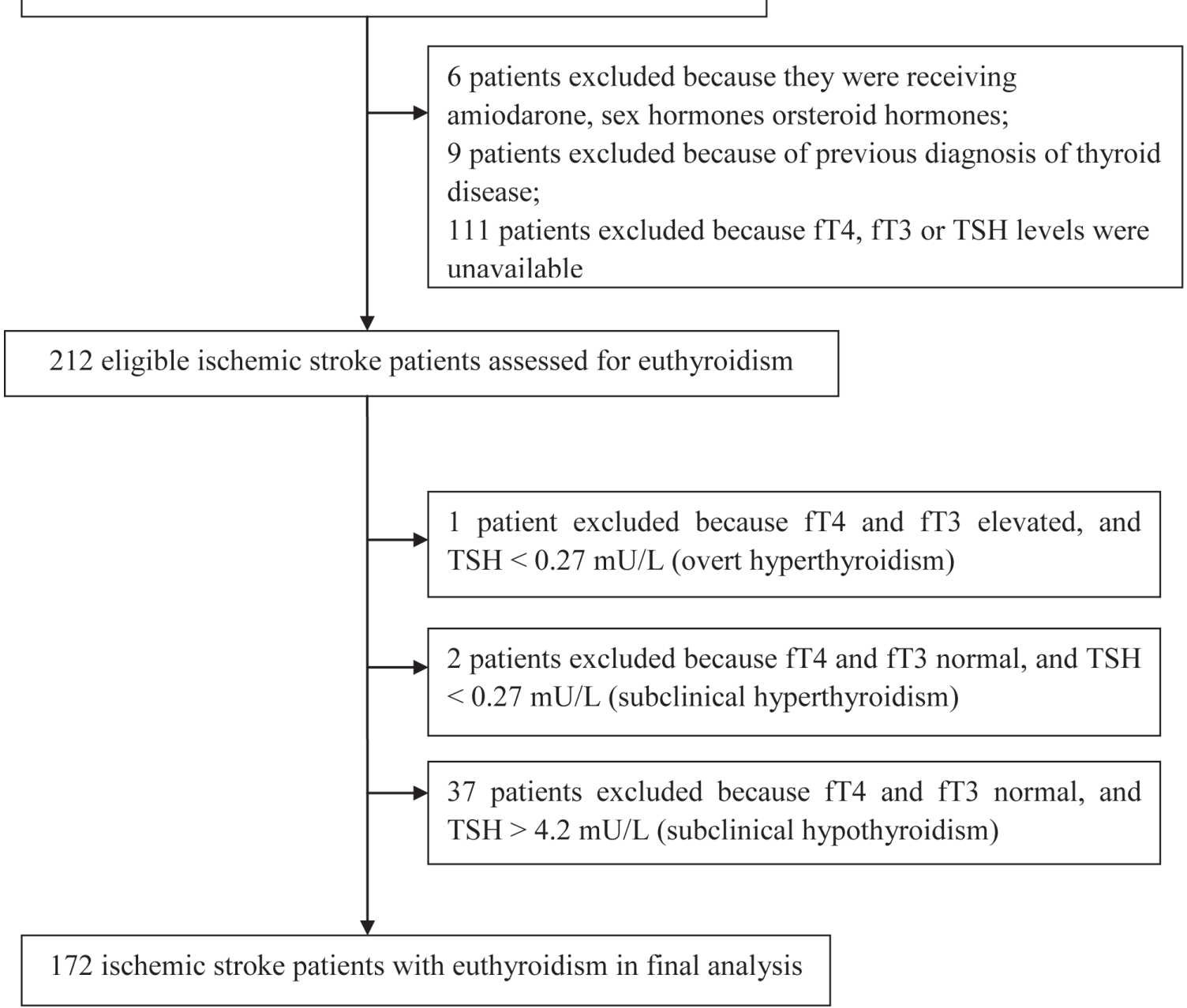

Figure 1: Study population and algorithm 
fT4 levels and carotid atheromatous plaques cannot be explored. Second, the patients we excluded were more likely to be female; this may have confounded our results, since the function of the hypothalamic-pituitary-thyroid (HPT) axis shows subtle sex differences [39], and men are more likely than women to have atherosclerosis [40]. To reduce the potential effects of such bias, we adjusted for age, gender, hyperlipidemia, and previous smoking in the multivariate analysis, which still indicated a significant relationship between low fT4 levels and carotid atheromatous plaques. Third, we measured fT4, fT3 and TSH levels only once and we did not measure thyroid autoantibody levels. This may have led to misdiagnosis of thyroid disease in some cases, since levels of thyroid hormones, especially $\mathrm{TSH}$, can vary in patients with acute ischemic stroke $[38,41]$.To reduce the potential confounding effects of non-thyroidal illness on thyroid function, we excluded patients who had abnormal TSH values or who were taking thyroid medication. Longitudinal studies involving larger samples are required to verify our findings on the influence of thyroid function on carotid atheromatous plaques and intracranial arterial stenosis.

\section{CONCLUSIONS}

Low fT4 levels were independently associated with carotid atheromatous plaques in a consecutive sample of Chinese ischemic stroke patients with euthyroidism. In contrast, no association was found between any of the three thyroid hormones tested and intracranial artery stenosis.

\section{MATERIALS AND METHODS}

This study involved retrospective analysis of medical records that had been entered prospectively into the Chengdu Stroke Registry, a database on consecutive ischemic stroke patients treated at West China Hospital since 2005. The study protocol was approved by the Scientific Research Department of West China Hospital. Written informed consent was obtained from participants or their guardians.

The present study involved the set of Registry patients admitted to the neurology department of West China Hospital, Sichuan University between February 2010 and March 2012 [33].Patients were diagnosed with first-ever or recurrent stroke according to World Health Organization(WHO) criteria [42]. Diagnosis was confirmed using computed tomography (CT) or magnetic resonance imaging (MRI).All patients underwent a thorough stroke workup $[33,43]$ in accordance with international standards, including neurological examination, brain CT or MRI (T1, T2, and angiography), CT angiography of the aortic arch and carotid arteries, 12lead electrocardiography, and blood biochemistry.
Patients were excluded from the study if (1)they had previously been prescribed amiodarone, sex hormones or steroid hormones; (2)they had previously been diagnosed with thyroid disease; or (3)their levels of free triiodothyronine (fT3), free thyroxine (fT4), or thyroidstimulating hormone(TSH) on the morning after hospital admission were unavailable.

Data were collected at the time of patient assessment using a standardized form. We collected patient demographic characteristics (age and gender) and stroke risk factors (hyperlipidemia, hypertension, diabetes mellitus, smoking consumption, and alcohol consumption). Stroke severity on admission was assessed using the National Institutes of Health Stroke Scale (NIHSS) score [44].

Blood samples were collected from each participant on the morning following admission. Levels of fT3, fT4 and TSH were measured using commercial radioimmunoassay kits and compared to the following normal reference ranges: fT3, 3.6-7.5 pmol/L; fT4, 12-22pmol/L; and TSH, 0.27-4.2 mU/L. During analysis, patients were assigned to quartiles depending on their levels of each hormone. The ranges for fT3 quartiles (pmol/L) were as follows: Quartile1, $\leq 3.46$; Quartile 2, 3.46-4.08; Quartile 3, 4.08-4.57; and Quartile 4, $\geq 4.57$. The ranges for fT4 quartiles (pmol/L) were as follows: Quartile1, $\leq 14.93$; Quartile 2, 14.93-16.08; Quartile 3, 16.08-18.01; and Quartile 4, $\geq 18.01$. The ranges for TSH quartiles (mU/L) were as follows: Quartile1, $\leq 1.09$; Quartile 2, 1.09-1.78; Quartile 3, 1.78-2.40; and Quartile $4, \geq 2.40$.

Diagnosis of intracranial artery stenosis [45-46] was based on $\geq 50 \%$ reduction in the luminal diameter of at least one major intracranial artery, defined as the intracranial internal carotid artery, anterior cerebral artery, middle cerebral artery, posterior cerebral artery, posterior inferior cerebellar artery, intracranial vertebral artery, or basilar artery. Luminal diameter was determined by CT angiograms, on which arteries usually appear homogeneously full of contrast material, and arterial walls appear as a sharp boundary [33]. Diagnosis of a carotid atheromatous plaque [33] was based on the absence of contrast material adjacent to the arterial wall. Two neurologists blinded to clinical information independently evaluated CT angiograms. A third neurologist arbitrated in case of disagreement, and a consensus decision was reached. The inter-class correlation coefficient (ICC) for the two reviewers was 0.876 (95\% CI 0.720-0.816), indicating very good inter-observer agreement.

Data for continuous variables were reported as mean \pm standard deviation (SD), and data for categorical variables as absolute or relative frequencies. Intergroup differences in categorical variables were assessed for significance using the chi-squared or Fisher's exact tests, while differences in continuous variables were assessed using one-way analysis of variance (ANOVA) or the 
Mann-Whitney U test. Patients were first compared based on the raw (continuous) values of thyroid hormones. Then they were classified into quartiles for logistic regression to identify associations of thyroid function with intracranial artery stenosis or carotid atheromatous plaques. Variables with $P<0.1$ in univariate analysis were included in multivariate logistic regression. All statistical analysis was performed using SPSS 20.0 (IBM, Chicago, IL, USA). Two-sided $P<0.05$ was considered to be statistically significant.

\section{ACKNOWLEDGMENTS AND FUNDING}

This research was supported by the Science and technology infrastructure projects of Sichuan Province (NO.2012JCPT008), and Chengdu Science and Technology Public Welfare Project (2014-HM01-00398$\mathrm{SF})$.

\section{CONFLICTS OF INTEREST}

The authors declare no conflicts of interest.

\section{REFERENCES}

1. Johnston SC, Mendis S, Mathers CD. Global variation in stroke burden and mortality: estimates from monitoring, surveillance, and modelling. Lancet Neurol. 2009; 8:345354.

2. Liu M, Wu B, Wang WZ, Lee LM, Zhang SH, Kong LZ. Stroke in China: epidemiology, prevention, and management strategies. Lancet Neurol. 2007; 6:456-464.

3. Lloyd-Jones D, Adams R, Carnethon M, De Simone G, Ferguson TB, Flegal K, Ford E, Furie K, Go A, Greenlund K, Haase N, Hailpern S, Ho M, et al. Heart disease and stroke statistics - 2009 update: a report from the American Heart Association Statistics Committee and Stroke Statistics Subcommittee. Circulation. 2009; 119:e21-181.

4. European Carotid Surgery Trialists' Collaborative Group. MRC European Carotid Surgery Trial: interim results for symptomatic patients with severe $(70-99 \%)$ or with mild (0-29\%) carotid stenosis. Lancet. 1991; 337:1235-1243.

5. North American Symptomatic Carotid Endarterectomy Trial Collaborators. Beneficial effect of carotid endarterectomy in symptomatic patients with high-grade carotid stenosis. New Engl J Med. 1991; 325:445-453.

6. Hennerici M, Hülsbömer HB, Hefter H, Lammerts D, Rautenberg W. Natural history of asymptomatic extracranial arterial disease. Results of a long-term prospective study. Brain. 1987; 110:777-791.

7. Wityk RJ, Lehman D, Klag M, Coresh J, Ahn H, Litt B. Race and sex differences in the distribution of cerebral atherosclerosis. Stroke. 1996; 27:1974-1980.

8. Feldmann E, Daneault N, Kwan E, Ho KJ, Pessin MS,
Langenberg P, Caplan LR. Chinese-white differences in the distribution of occlusive cerebrovascular disease. Neurology. 1990; 40:1541-1545.

9. Sacco RL, Kargman DE, Gu Q, Zamanillo MC. Raceethnicity and determinants of intracranial atherosclerotic cerebral infarction: The Northern Manhattan Stroke Study. Stroke. 1995; 26:14-20.

10. van Tienhoven-Wind LJ, Dullaart RP. Low-normal thyroid function and the pathogenesis of common cardio-metabolic disorders. Eur J Clin Invest. 2015; 45:494-503.

11. Chaker L, Baumgartner C, den Elzen WP, Ikram MA, Blum MR, Collet TH, Bakker SJ, Dehghan A, Drechsler C, Luben RN, Hofman A, Portegies ML, Medici M, et al. Subclinical Hypothyroidism and the Risk of Stroke Events and Fatal Stroke: An Individual Participant Data Analysis. J Clin Endocrinol Metab. 2015; 100:2181-2191.

12. Chaker L, Baumgartner C, den Elzen WP, Collet TH, Ikram MA, Blum MR, Dehghan A, Drechsler C, Luben RN, Portegies ML, Iervasi G, Medici M, Stott DJ, et al. Thyroid Function Within the Reference Range and the Risk of Stroke: An Individual Participant Data Analysis. J Clin Endocrinol Metab. 2016; 101:4270-4282.

13. Hak AE, Pols HA, Visser TJ, Drexhage HA, Hofman A, Witteman JC. Subclinical hypothyroidism is an independent risk factor for atherosclerosis and myocardial infarction in elderly women: the Rotterdam Study. Ann Intern Med. 2000; 132:270-278.

14. Kvetny J, Heldgaard PE, Bladbjerg EM, Gram J. Subclinical hypothyroidism is associated with a low-grade inflammation, increased triglyceride levels and predicts cardiovascular disease in males below 50 years. Clin Endocrinol (Oxf). 2004;61:232-238.

15. Kim SK, Kim SH, Park KS, Park SW, Cho YW. Regression of the increased common carotid artery-intima media thickness in subclinical hypothyroidism after thyroid hormone replacement. Endocr J. 2009; 56:753-758.

16. Nagasaki T, Inaba M, Henmi Y, Kumeda Y, Ueda M, Tahara H, Ishimura E, Onoda N, Ishikawa T, Nishizawa Y. Change in von Willebrand factor and carotid intima-media thickness in hypothyroid patients with normal thyroid function after levothyroxine replacement therapy. Eur J Endocrinol. 2004; 150:125-131.

17. Jublanc C, Bruckert E, Giral P, Chapman MJ, Leenhardt L, Carreau V, Turpin G. Relationship of circulating C-reactive protein levels to thyroid status and cardiovascular risk in hyperlipidemic euthyroid subjects: low free thyroxine is associated with elevated hsCRP. Atherosclerosis. 2004; 172:7-11.

18. Takamura N, Akilzhanova A, Hayashida N, Kadota K, Yamasaki H, Usa T, Nakazato M, Maeda T, Ozono Y, Aoyagi K. Thyroid function is associated with carotid intima-media thickness in euthyroid subjects. Atherosclerosis. 2009;204:e 77-81.

19. Dullaart RP, de Vries R, Roozendaal C, Kobold AC, Sluiter 
WJ. Carotid arteryintima media thickness is inversely related to serum free thyroxine in euthyroid subjects. Clin Endocrinol (Oxf). 2007; 67:668-673.

20. Zhou Y, Zhao L, Wang T, Hong J, Zhang J, Xu B, Huang $\mathrm{X}, \mathrm{Xu} \mathrm{M}, \mathrm{Bi}$ Y. Free Triiodothyronine Concentrations are Inversely Associated with Elevated Carotid Intima-Media Thickness in Middle-Aged and Elderly Chinese Population. J Atheroscler Thromb. 2016; 23:216-224.

21. Peixoto de Miranda ÉJ, Bittencourt MS, Pereira AC, Goulart AC, Santos IS, Lotufo PA, Bensenor IM. Subclinical hypothyroidism is associated with higher carotid intimamedia thickness in cross-sectional analysis of the Brazilian Longitudinal Study of Adult Health (ELSA-Brasil). Nutr Metab Cardiovasc Dis. 2016; 26:915-921.

22. Jeong SK, Seo JY, Nam HS, Park HK. Thyroid function and internal carotid artery stenosis in ischemic stroke. Endocr J. 2010; 57:711-718.

23. Sevuk U, Bahadir MV, Altindag R, Baysal E, Altintas B, Yaylak B, Adiyaman MS, Ay N. Relationship between thyroid function and carotid artery plaque ulceration. Acta Neurol Belg. 2015; 115:581-587.

24. Dörr M, Ruppert J, Wallaschofski H, Felix SB, Völzke $H$. The association of thyroid function and heart valve sclerosis. Results from a population-based study. Endocr J. 2008; 55:495-502.

25. Gumieniak O, Perlstein TS, Hopkins PN, Brown NJ, Murphey LJ, Jeunemaitre X, Hollenberg NK, Williams GH. Thyroid function and blood pressure homeostasis in euthyroid subjects. J Clin Endocrinol Metab. 2004; 89:3455-3461.

26. Roos A, Bakker SJ, Links TP, Gans RO, Wolffenbuttel $\mathrm{BH}$. Thyroid function is associated with components of the metabolic syndrome in euthyroid subjects. J Clin Endocrinol Metab. 2007; 92: 491-496.

27. Fernández-Real JM, López-Bermejo A, Castro A, Casamitjana R, Ricart W. Thyroid function is intrinsically linked to insulin sensitivity and endothelium-dependent vasodilation in healthy euthyroid subjects. J Clin Endocrinol Metab. 2006; 91: 3337-3343.

28. Roef GL, Rietzschel ER, Van Daele CM, Taes YE, De Buyzere ML, Gillebert TC, Kaufman JM. Triiodothyronine and free thyroxine levels are differentially associated with metabolic profile and adiposity-related cardiovascular risk markers in euthyroid middle-aged subjects. Thyroid.2014; 24: 223-231.

29. Ojamaa K, Klemperer JD, Klein I. Acute effects of thyroid hormone on vascular smooth muscle. Thyroid. 1996; 6: 505-512.

30. Shi Z, Zhang X, Chen Z, Liebeskind DS, Lou M. Elevated thyroid autoantibodies and intracranial stenosis in stroke at an early age. Int J Stroke. 2014; 9:735-740.

31. Zhang X, Chen Z, Shi Z, Lou M. Correlation between thyroid autoanti-bodies and intracranial arterial stenosis in stroke patients with hyper-thyroidism. J Neurol Sci. 2012; 318:82-84

32. Liu HM, Tu YK, Yip PK, Su CT. Evaluation of intracranial and extracranial carotid steno-occlusive diseases in Taiwan Chinese patients with MR angiography: preliminary experience. Stroke. 1996; 27:650-653.

33. Cui X, Wu S, Zeng Q, Xiao J, Liu M. Detecting atheromatous plaques in the aortic arch or supra-aortic arteries for more accurate stroke subtype classification. Int J Neurosci. 2015; 125:123-129.

34. De Silva DA, Woon FP, Lee MP, Chen CP, Chang HM, Wong MC. South Asian patients with ischemic stroke: intracranial large arteries are the predominant site of disease. Stroke. 2007; 38:2592-2594.

35. Huang YN, Gao S, Li SW, Huang Y, Li JF, Wong KS, Kay R. Vascular lesions in Chinese patients with transient ischemic attacks. Neurology. 1997; 48:524-525.

36. Ratanakorn D, Keandoungchun J, Tegeler CH. Coexistent extra- and intracranial stenosis, cervical atherosclerosis, and abnormal ankle brachial index in acute ischemic stroke. J Stroke Cerebrovasc Dis. 2012;21:782-789.

37. Wong KS, Huang YN, Gao S, Lam WW, Chan YL, Kay R. Intracranial stenosis in Chinese patients with acute stroke. Neurology. 1998; 50:812-813.

38. Theodoropoulou A, Metallinos IC, Elloul J, Taleli P, Lekka N, Vagenakis AG, Kyriazopoulou V. cortisol secretion and thyroid function in patients with stroke of mild severity. Horm Metab Res. 2006; 38:587-591.

39. Brown SJ, Bremner AP, Hadlow NC, Feddema P, Leedman PJ, O'Leary PC, Walsh JP. The log TSH-free T4 relationship in a community-based cohort is non-linear and is influenced by age, smoking and thyroid peroxidase antibody status. Clin Endocrinol (Oxf). 2016; 85:789-796.

40. Howard G, Sharrett AR, Heiss G, Evans GW, Chambless LE, Riley WA, Burke GL. Carotid artery intimal-medial thickness distribution in general populations as evaluated by B-mode ultrasound. ARIC Investigators. Stroke. 1993; 24:1297-1304.

41. Schwarz S, Schwab S, Klinga K, Maser-Gluth C, Bettendorf M. Neuroendocrine changes in patients with acute space occupying ischaemic stroke. J Neurol Neurosurg Psychiatry. 2003; 74:725-727.

42. Aho K, Harmsen P, Hatano S, Marquardsen J, Smirnov VE, Strasser T. Cerebrovascular disease in the community: Results of a WHO collaborative study. Bull World Health Organ. 1980; 58:113-130.

43. Kong FY, Tao WD, Hao ZL, Liu M. Predictors of one-year disability and death in Chinese hospitalized women after ischemic stroke. Cerebrovasc Dis. 2010; 29:255-262.

44. Brott T, Adams HP Jr, Olinger CP, Marler JR, Barsan WG, Biller J, Spilker J, Holleran R, Eberle R, Hertzberg $\mathrm{V}$. Measurements of acute cerebral infarction: a clinical examination scale. Stroke. 1989; 20: 864-870. 
45. Chimowitz MI, Kokkinos J, Strong J, Brown MB, Levine SR, Silliman S, Pessin MS, Weichel E, Sila CA, Furlan AJ. The Warfarin Aspirin Symptomatic Intracranial Disease Study. Neurology. 1995; 45:1488-1493.

46. Chimowitz MI, Lynn MJ, Howlett-Smith H, Stern BJ, Hertzberg VS, Frankel MR, Levine SR, Chaturvedi S, Kasner SE, Benesch CG, Sila CA, Jovin TG, Romano JG, et al. Comparison of warfarin and aspirin for symptomatic intracranial arterial stenosis. New Engl J Med. 2005; 352:1305-1316. 